Article

\title{
Impact of Recommended Maternal Vaccination Programs on the Clinical Presentation of SARS-CoV-2 Infection: A Prospective Observational Study
}

\author{
Maria Luisa de la Cruz Conty ${ }^{1}$, Maria Begoña Encinas Pardilla ${ }^{2}$, Marta Garcia Sanchez ${ }^{3, *(0)}$, \\ Laura Gonzalez Rodriguez ${ }^{4}$, Marta Luisa Muner-Hernando ${ }^{5}$, Ana Royuela Vicente ${ }^{6}$, Pilar Pintado Recarte ${ }^{7}$, \\ Alicia Martinez Varea ${ }^{8}$, Clara Martinez Diago 9 ${ }^{(0)}$, Sara Cruz Melguizo ${ }^{2}$, Oscar Martinez-Perez ${ }^{2,10}$ \\ and on behalf of the Spanish Obstetric Emergency Group ${ }^{\dagger}$
}

check for

updates

Citation: de la Cruz Conty, M.L.;

Encinas Pardilla, M.B.; Garcia

Sanchez, M.; Gonzalez Rodriguez, L.;

Muner-Hernando, M.L.; Royuela

Vicente, A.; Pintado Recarte, P.;

Martinez Varea, A.; Martinez Diago,

C.; Cruz Melguizo, S.; et al. Impact of

Recommended Maternal Vaccination

Programs on the Clinical Presentation of SARS-CoV-2 Infection: A Prospective Observational Study. Vaccines 2021, 9 ,

31. https://doi.org/10.3390/

vaccines 9010031

Received: 21 December 2020

Accepted: 6 January 2021

Published: 8 January 2021

Publisher's Note: MDPI stays neutral with regard to jurisdictional clai$\mathrm{ms}$ in published maps and institutional affiliations.

Copyright: (C) 2021 by the authors. Licensee MDPI, Basel, Switzerland. This article is an open access article distributed under the terms and conditions of the Creative Commons Attribution (CC BY) license (https:// creativecommons.org/licenses/by/ $4.0 /)$
1 Fundacion de Investigacion Biomedica, Puerta de Hierro University Hospital of Majadahonda, 28222 Madrid, Spain; farmcruz@gmail.com

2 Department of Gynecology and Obstetrics, Puerta de Hierro University Hospital of Majadahonda, 28222 Madrid, Spain; mariabegona.encinas@salud.madrid.org (M.B.E.P.) ; scruzm@salud.madrid.org (S.C.M.); omartinez@ucam.edu (O.M.-P.)

3 Department of Gynecology and Obstetrics, Quironsalud Malaga University Hospital, 29004 Malaga, Spain

4 Department of Gynecology and Obstetrics, Alvaro Cunqueiro Hospital of Vigo, 36213 Pontevedra, Spain; Laura.Gonzalez.Rodriguez@sergas.es

5 Department of Gynecology and Obstetrics, La Paz University Hospital, 28046 Madrid, Spain; martal.muner@salud.madrid.org

6 *Biostatistics Unit, Puerta de Hierro Biomedical Research Institute (IDIPHISA-CIBERESP), 28222 Madrid, Spain; aroyuela@idiphim.org

7 Department of Gynecology and Obstetrics, Gregorio Marañon University Hospital, 28007 Madrid, Spain; ppintado@salud.madrid.org

8 Department of Gynecology and Obstetrics, La Fe University and Polytechnic Hospital, 46026 Valencia, Spain; martinez_alivar@gva.es

9 Department of Gynecology and Obstetrics, Doctor Josep Trueta University Hospital of Girona, 17007 Girona, Spain; clmartinez.girona.ics@gencat.cat

10 Departamento de Obstetricia y Ginecología, Universidad Autónoma de Madrid, 28029 Madrid, Spain

* Correspondence: mgsanchez.mlg@quironsalud.es

$\dagger$ A list of the Spanish Obstetric Emergency Group collaborators appears in the Acknowledgements section.

Abstract: The COVID-19 pandemic has raised questions about the possible cross immunity resulting from common vaccination programs and SARS-CoV-2 infection. Therefore, the Spanish Obstetric Emergency group performed a multicenter prospective study on the vaccination status of Influenza and Tdap (diphtheria, tetanus and pertussis vaccine boost administered in adulthood) in consecutive cases of SARS-CoV-2 infection in a pregnancy cohort, in order to assess its possible association with the clinical presentation and severity of symptoms of SARS-CoV-2 infection, as well as to determine the factors that may affect vaccination adherence. A total of 1150 SARS-CoV-2 positive pregnant women from 78 Spanish hospitals were analyzed: 183 had not received either vaccine, 23 had been vaccinated for Influenza only, 529 for Tdap only and 415 received both vaccines. No association was observed between the vaccination status and the clinical presentation of SARS-CoV-2 infection and/or the severity of symptoms. However, a lower adherence to the administration of both vaccines was observed in the Latin-American subgroup. Based on the results above, we reinforce the importance of maternal vaccination programs in the actual pandemic. Health education campaigns should be specially targeted to groups less likely to participate in these programs, as well as for a future SARS-CoV-2 vaccination campaign.

Keywords: SARS-CoV-2; covid 19; pregnancy; passive immunization; maternal immunization; influenza vaccines; diphtheria tetanus pertussis vaccine 


\section{Introduction}

The COVID-19 pandemic has raised questions among the scientific community about the possible cross immunity resulting from common vaccination programs and SARS-CoV2 infection. Although evidence at the molecular level has not been provided yet, there are studies that report an association between Influenza vaccination and a lower risk of serious illness and/or death among COVID-19 patients [1-4]. In addition, a lower rate of Influenza vaccination has been observed among COVID-19 patients requiring hospitalization, intensive care or respiratory support, and an inversely proportional association was also found between Influenza vaccination and mortality risk in these patients [5].

It has also been suggested that the DTP vaccine (a combination of vaccines against diphtheria, tetanus and pertussis) could confer potential cross-reactivity to SARS-CoV-2 due to the existence of peptide matches between both, though clinical trials and/or broad observational studies are needed to confirm this hypothesis built on molecular findings [6].

On the other hand, the theoretical associations above can be affected by multiple factors that must be studied, such as ethnicity. It seems that the progression of COVID-19 is worse in people of certain ethnicities, with an increase in Intensive Care Unit (ICU) admission of Hispanic and non-Hispanic black pregnant women [7,8]; in turn, it should be considered that the adherence to vaccination programs varies according to ethnicity, even in countries with a national public health system.

Based on these theories, and as pregnancy is an exceptional period in adulthood in which Influenza and DTP vaccines are administered coincidentally or closely, we performed an observational prospective study in approximately 1400 SARS-CoV-2 positive pregnant women diagnosed from 26 February to 5 November 2020 in 78 Spanish hospitals. The objective was to assess the possible association between the clinical presentation and severity of symptoms of SARS-CoV-2 infection with their Influenza and DTP vaccination status. Moreover, we examined the factors that may affect Influenza and DTP vaccination adherence, taking into account that in Spain, with a public and universal health system, these vaccines are accessible and free for the population and strongly recommended for pregnant women. Finally, the possible relationship between these factors and the clinical presentation of the SARS-CoV-2 infection was also analyzed.

\section{Materials and Methods}

This was a multicenter prospective study of consecutive cases of SARS-CoV-2 infection in a pregnancy cohort registered by the Spanish Obstetric Emergency group [9]. The registry protocol was approved by the coordinating hospital's Medical Ethics Committee on 23 March 2020 (reference number: PI 55/20) and each collaborating center subsequently obtained protocol approval locally; the registry protocol is available in ClinicalTrials.gov (NCT04558996). A complete list of the 78 centers contributing to the study is provided in Table S1. Upon recruitment, given the contagiousness of the disease and the lack of personal protection equipment, mothers consented by either signing a document, when possible, or by giving permission verbally, which was recorded in the patient's chart. A specific database was designed for recording information regarding SARS-CoV-2 infection in pregnancy and the data were entered by the lead researcher for each center after delivery.

The Influenza and DTP vaccinations are included in the Spanish protocol for care and control of pregnancies $[10,11]$ and both vaccines are free and very accessible to pregnant women through the National Health Care System. The DTP vaccine used is the Tdap, a DTP vaccine boost administered in adulthood $\left(\right.$ Boostrix $\left.^{\circledR}\right)$.

\subsection{Infected Cohort}

During the period of the study, from 26 February to 5 November 2020, we selected COVID-19 obstetric patients detected by screening for SARS-CoV-2 infection at admission in the delivery ward, or by testing suspicious cases that came into hospital due to COVID-19 symptoms. SARS-CoV-2 infection was diagnosed by positive double-sampling polymerasechain-reaction (PCR) from nasopharyngeal swabs. All positive cases with known Influenza 
and Tdap vaccination status were included in the study. The cases were classified as asymptomatic and symptomatic, and the latter was stratified into three groups: mildmoderate symptoms, pneumonia and complicated pneumonia/shock (with ICU admission and/or mechanical ventilation and/or septic shock) [12].

Information regarding the demographic characteristics of each pregnant woman, Influenza and Tdap vaccination, comorbidities, previous and current obstetric history were extracted from the clinical and verbal history of the patient.

\subsection{Statistical Analysis}

The variable maternal age (years) was tested for normal distribution using the Kolmogorov-Smirnov test. Descriptive data are presented as median (interquartile range, IQR) or number (percentage). $p$-values were obtained by the Kruskal-Wallis test and post-hoc pairwise comparison for the numerical variable and Pearson Chi-squared test for categorical variables. A $p$-value below 0.05 was considered statistically significant. In case of a statistically significant association between Influenza and/or Tdap vaccinations and the clinical presentation of SARS-CoV-2 infection, the potential influence of known and suspected measured confounding factors was controlled with multivariable logistic and multinomial regression modeling, after checking scientifically sound two-way interactions.

Data were analyzed using SPSS version 20 (IBM Inc., Chicago, IL, USA) and the lme4 package in R, version 3.4 (RCore Team, 2017) [13].

\section{Results}

\subsection{Description of the Infected Cohort According Their Vaccination}

One thousand three hundred and forty-seven positive SARS CoV-2 pregnant women were identified, of which 197 were excluded because they did not provide complete information of their Influenza and/or Tdap vaccination status. Thus, a total of one thousand hundred fifty (1150) patients were analyzed: 183 had not received either vaccine, 23 had been vaccinated for Influenza only, 529 for Tdap only and 415 received both vaccines (Figure 1).

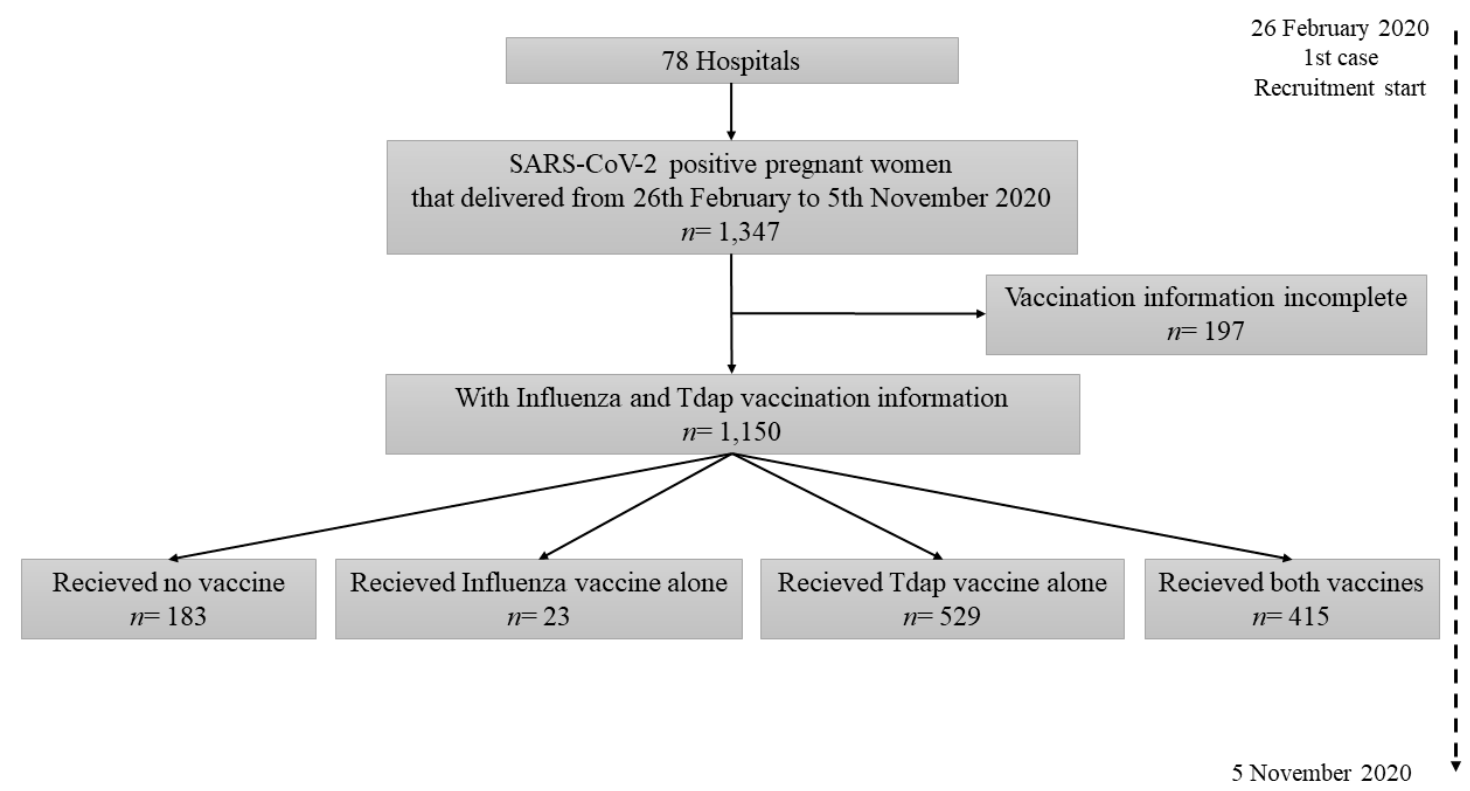

Figure 1. Flow chart of the study data.

Table 1 shows the baseline characteristics of patients stratified into the four vaccination groups mentioned above. Pregnant women vaccinated for both Influenza and Tdap significantly differed from other groups: these women were older $(p=0.013)$, the proportion of Latin-Americans in this group was significantly lower $(19.6 \%$ vs. above $26.0 \%$ in the 
remaining vaccination groups, $p=0.001$, Figure 2) and in vitro fertilization was significantly more frequent among these patients $(8.7 \%$ vs. below $5.0 \%$ in other groups, $p=0.025)$. Private hospital attendance and parity showed no significant differences between groups, while the proportion of pregnant women with respiratory comorbidities in the Influenza vaccine group quadrupled the observed in the remaining groups $(17.4 \%$ vs. below $4.5 \%$ in the remaining vaccination groups, $p=0.007$ ).

Table 1. Baseline characteristics of the study participants and by vaccination group.

\begin{tabular}{|c|c|c|c|c|c|c|}
\hline \multirow[b]{2}{*}{ Baseline Characteristics } & \multirow{2}{*}{$\begin{array}{c}\text { Total } \\
N=1150\end{array}$} & \multicolumn{5}{|c|}{ Vaccination Groups } \\
\hline & & $\begin{array}{c}\text { No Vaccine } \\
N=183\end{array}$ & $\begin{array}{l}\text { Influenza Alone } \\
\qquad N=23\end{array}$ & $\begin{array}{c}\text { Tdap Alone } \\
N=529\end{array}$ & $\begin{array}{l}\text { Both Vaccines } \\
\qquad N=415\end{array}$ & $p$-Value \\
\hline $\begin{array}{c}\text { Maternal Age } \\
\text { (Years; Median/IQR) } \\
\text { Ethnicity }\end{array}$ & $33(28-37)$ & $32(26-36)$ & $33(26-39)$ & $33(28-36)$ & $33(29-37)$ & $0.013 *$ \\
\hline Latin-American & $308 / 1147$ (26.9) & $48(26.2)$ & $7(30.4)$ & $172 / 527(32.6)$ & $81 / 414(19.6)$ & \\
\hline Caucasian & $674 / 1147$ (58.8) & $107(58.5)$ & $14(60.9)$ & $280 / 527(53.1)$ & $273 / 414(65.9)$ & $0.001^{*}$ \\
\hline Other $^{\mathrm{a}}$ & $165 / 1147(14.4)$ & $28(15.3)$ & $2(8.7)$ & $75 / 527(14.2)$ & $60 / 414(14.5)$ & \\
\hline Private hospital & $83(7.2)$ & $14(7.7)$ & $0(0.0)$ & $31(5.9)$ & $38(9.2)$ & 0.131 \\
\hline Nulliparity & $455(39.6)$ & $78(42.6)$ & $12(52.2)$ & $206(38.9)$ & $159(38.3)$ & 0.457 \\
\hline Preterm delivery ( $<37$ weeks) & $113 / 1148(9.8)$ & $29(15.8)$ & $5(21.7)$ & $37(7.0)$ & $42 / 413(10.2)$ & $0.001 *$ \\
\hline In vitro fertilization & $69(6.0)$ & $7(3.8)$ & $0(0.0)$ & $26(4.9)$ & $36(8.7)$ & 0.025 * \\
\hline Respiratory comorbidities & $44(3.8)$ & $8(4.4)$ & $4(17.4)$ & $17(3.2)$ & $15(3.6)$ & $0.007 *$ \\
\hline Chronic lung disease & $3(0.3)$ & $1(0.5)$ & $0(0.0)$ & $1(0.2)$ & $1(0.2)$ & 0.863 \\
\hline Asthma & $43(3.7)$ & $8(4.4)$ & $4(17.4)$ & $17(3.2)$ & $14(3.4)$ & 0.005 * \\
\hline
\end{tabular}

Data are shown as n (\% of total with data), except where otherwise indicated. IQR: Interquartile Range ${ }^{a}$ Arab, Black, East-Asian, South-Asian and West-Asian * Statistically significant differences.

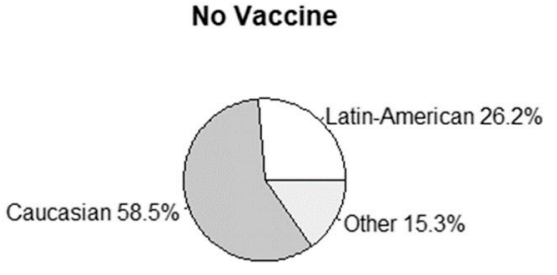

Tdap Vaccine alone

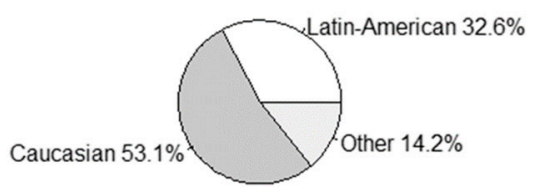

Influenza Vaccine alone

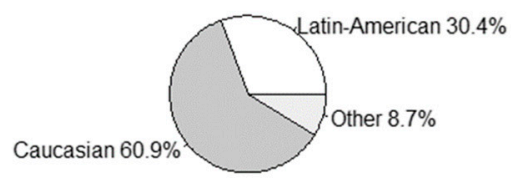

Both Vaccines

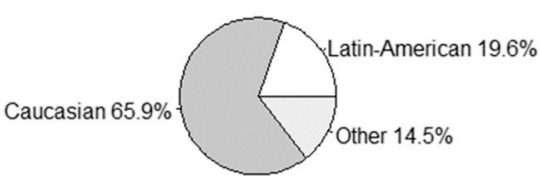

Figure 2. Ethnicity distribution by vaccination group.

On the other hand, and independently of the vaccination status of patients, an association between the type of hospital and ethnicity was observed, being private hospital attendance five times more frequent in Caucasian women $(10.8 \%$ vs. $2.1 \%$ in other ethnicities, $p<0.001$ ).

\subsection{Clinical Presentation of SARS-CoV-2 Infection According to the Vaccination of Patients}

Clinical presentation of SARS-CoV-2 infection is shown in Table 2. The observed distribution of asymptomatic and symptomatic patients was similar between vaccination groups (approximately 50\% vs. 50\%), with the exception of those patients vaccinated only for Influenza (26.1\% vs. $73.9 \%$, respectively); even so, this difference was not statistically significant $(p=0.051)$. When analyzed by clinical presentation, approximately three quarters of symptomatic patients had mild-moderate symptoms (cough, anosmia, fatigue/discomfort, fever, dyspnea, etc.) in the groups that received both vaccines, Tdap vaccine alone and no vaccine at all, while one quarter of symptomatic pregnant women 
developed more severe symptoms (pneumonia with/without ICU admission, mechanical ventilation and/or septic shock). However, the distribution of symptoms was slightly different in the group vaccinated only for Influenza, where the proportion of symptomatic patients who developed pneumonia or complicated pneumonia/shock increased up to $41.2 \%$ although, as in the previous case, these differences were not statistically significant $(p=0.433)$.

Table 2. Clinical presentation of SARS-CoV-2 infection by vaccination group.

\begin{tabular}{|c|c|c|c|c|c|}
\hline $\begin{array}{l}\text { Clinical Presentation of } \\
\text { SARS-CoV-2 infection }\end{array}$ & $\begin{array}{c}\text { No Vaccine } \\
N=183\end{array}$ & $\begin{array}{c}\text { Influenza Alone } \\
\qquad N=23\end{array}$ & $\begin{array}{c}\text { Tdap Alone } \\
\quad N=529\end{array}$ & $\begin{array}{l}\text { Both Vaccines } \\
\qquad N=415\end{array}$ & $p$-Value \\
\hline Asymptomatic & $85(46.4)$ & $6(26.1)$ & $276(52.2)$ & $217(52.3)$ & \multirow{2}{*}{0.051} \\
\hline Symptomatic & $98(53.6)$ & $17(73.9)$ & $253(47.8)$ & $198(47.7)$ & \\
\hline Mild-moderate symptoms & $70 / 98(71.4)$ & $10 / 17(58.8)$ & $182 / 253(71.9)$ & $147 / 198(74.2)$ & \multirow{3}{*}{0.433} \\
\hline Pneumonia & $22 / 98(22.4)$ & $5 / 17(29.4)$ & $62 / 253(24.5)$ & $46 / 198(23.2)$ & \\
\hline Complicated pneumonia ${ }^{a} /$ shock & $6 / 98(6.1)$ & 2/17 (11.8) & $9 / 253(3.6)$ & $5 / 198(2.5)$ & \\
\hline
\end{tabular}

Data are shown as $\mathrm{n}\left(\%\right.$ of total); ${ }^{\text {a }}$ with ICU admission and/or mechanical ventilation and/or septic shock.

\subsection{Baseline Characteristics of Asymptomatic and Symptomatic Patients}

Due to the absence of a statistically significant association of vaccination with the clinical presentation of SARS-CoV-2 infection, no multivariable analysis was carried out, but Table 3 was constructed to study baseline characteristics of asymptomatic and symptomatic patients that could confound the findings above. It was observed that among the symptomatic group there were twice as many patients with respiratory comorbidities than in the asymptomatic group (5.1\% vs. $2.6 \%$, respectively, $p=0.024)$ and more women from Latin-America (35.8\% vs. $18.2 \%$ in asymptomatic patients, $p<0.001$ ), as well as the proportion of Latin-American women increased up to $45.2 \%$ among patients with pneumonia or complicated pneumonia/shock $(p=0.032)$. Additionally, the use of private health care was less common among positive pregnant women who developed COVID-19 symptomatology $(4.4 \%$ vs. $9.9 \%$ of asymptomatic patients, $p<0.001)$, characteristic in turn associated with ethnicity, as mentioned above.

Table 3. Baseline characteristics by clinical presentation of SARS-CoV-2 infection.

\begin{tabular}{|c|c|c|c|c|c|c|c|}
\hline \multirow[t]{2}{*}{$\begin{array}{c}\text { Baseline } \\
\text { Characteristics }\end{array}$} & \multicolumn{3}{|c|}{$\begin{array}{l}\text { All Patients } \\
\quad N=1150\end{array}$} & \multicolumn{4}{|c|}{$\begin{array}{l}\text { Symptomatic Patients } \\
\qquad N=566\end{array}$} \\
\hline & $\begin{array}{c}\text { Asymptomatic } \\
\text { Patients } \\
N=584\end{array}$ & $\begin{array}{l}\text { Symptomatic } \\
\text { Patients } \\
N=566\end{array}$ & $p$-Value & $\begin{array}{l}\text { Mild-Moderate } \\
\text { Symptoms } \\
N=409\end{array}$ & $\begin{array}{l}\text { Pneumonia } \\
\qquad=135\end{array}$ & $\begin{array}{c}\text { Complicated } \\
\text { Pneumonia } \\
\text { c/Shock } \\
N=22\end{array}$ & $p$-Value \\
\hline $\begin{array}{c}\text { Maternal Age } \\
\text { (Years; Median/IQR) } \\
\text { Ethnicity }\end{array}$ & $32(28-36)$ & $33(28-37)$ & 0.153 & $33(28-37)$ & $33(28-37)$ & $32(26-38)$ & 0.848 \\
\hline $\begin{array}{l}\text { Latin-American } \\
\text { Caucasian }\end{array}$ & $\begin{array}{l}106 / 583(18.2) \\
375 / 583(64.3)\end{array}$ & $\begin{array}{l}202 / 564(35.8) \\
299 / 564(53.0)\end{array}$ & $<0.001 *$ & $\begin{array}{l}131 / 407(32.2) \\
231 / 407(56.8)\end{array}$ & $\begin{array}{l}63(46.7) \\
56(41.5)\end{array}$ & $\begin{array}{c}8(36.4) \\
12(54.5)\end{array}$ & 0.032 * \\
\hline Other ${ }^{a}$ & $102 / 583$ (17.5) & $63 / 564(11.2)$ & & $45 / 407(11.1)$ & $16(11.9)$ & $2(9.1)$ & \\
\hline Private hospital & $58(9.9)$ & $25(4.4)$ & $<0.001 *$ & $19(4.6)$ & $6(4.4)$ & $0(0.0)$ & 0.586 \\
\hline Nulliparity & $235(40.2)$ & $220(38.9)$ & 0.635 & $167(40.8)$ & $46(34.1)$ & $7(31.8)$ & 0.297 \\
\hline In vitro fertilization & $31(5.3)$ & $38(6.7)$ & 0.316 & $30(7.3)$ & $5(3.7)$ & $3(13.6)$ & 0.143 \\
\hline $\begin{array}{l}\text { Respiratory } \\
\text { comorbidities }\end{array}$ & $15(2.6)$ & $29(5.1)$ & $0.024 *$ & $22(5.4)$ & $5(3.7)$ & $2(9.1)$ & 0.515 \\
\hline Chronic lung disease & $1(0.2)$ & $2(0.4)$ & 0.619 & $0(0.0)$ & $2(1.5)$ & $0(0.0)$ & $0.041 *$ \\
\hline Asthma & $15(2.6)$ & $28(4.9)$ & $0.034 *$ & $22(5.4)$ & $4(3.0)$ & $2(9.1)$ & 0.351 \\
\hline
\end{tabular}

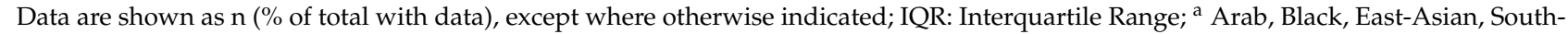
Asian and West-Asian; ${ }^{c}$ with ICU admission and/or mechanical ventilation and/or septic shock; ${ }^{*}$ Statistically significant differences. 


\section{Discussion}

The study we provide is part of one of the largest worldwide databases of pregnancy and SARS-CoV-2 with 78 hospitals involved and almost 1400 deliveries from infected pregnant women included (from 26th February to 5th November 2020, therefore, including cases of both the first and second COVID-19 wave), whether they were symptomatic or not. The main strength of this study is that the patients came from all over Spain, with their inherent demographic and healthcare differences, and they were users of public and private hospitals.

Our patients represent a unique population in terms of immunology and vaccination status, due to the immunomodulation variations that characterize pregnancies and it corresponds to an exceptional period in adulthood in which Influenza and Tdap vaccines are administered coincidentally or closely, except for some specific immunodeficiency situations. This represents the uniqueness of this study; a pioneer in analyzing the adherence to the recommended vaccines during pregnancy and the factors that may influence this adherence, as well as analyzing the possible relationship between them and the clinical presentation of the SARS-CoV-2 infection.

Vaccination against Influenza and pertussis in pregnancy is a recommendation supported by the WHO and is already applied in many countries, but despite the evidence demonstrated on safety and effectiveness, vaccination adherence is still moderate for pertussis and low for Influenza in pregnant women [14]. Spain has achieved high rates of coverage, although there exist clear differences between Tdap and Influenza $(80.1 \%$ vs. $40.6 \%$ for the 2018-2019 campaign in pregnant women) [15]. In our study of SARS-CoV-2 positive patients, we found similar rates of vaccine compliance $(82.1 \%$ and $38.1 \%$ for Tdap and Influenza vaccination, respectively), which confirms the representativeness of our participants and confers robustness of our study results.

When the vaccination analysis was stratified by ethnicity, a lower adherence to the administration of both vaccines was observed in the Latin-American subgroup; this coincides with the trend published in other countries for vaccination of racial minorities [16]. It seems that the observed patient profile who tends to complete the double vaccination in Spain corresponds to older Caucasian women, many of whom required in vitro fertilization techniques, a fact that may as well justify the higher frequency of private health care services attendance in this group and an increased awareness of the importance of their vaccination due to risk factors characteristic of in vitro fertilization users. These differences cannot be attributed in our case to the ease of access to the vaccines or their cost, since in Spain these two vaccines are free of cost and standardized for pregnant women throughout the country. Therefore, there are other factors such as cultural, beliefs, fears, health education, that come into play, which have not been the object of this study $[17,18]$.

No association was observed between the vaccination status of patients in the current pregnancy (no vaccination, Influenza or Tdap vaccine and double vaccination) and the clinical presentation of SARS-CoV-2 infection and/or the severity of symptoms (development of pneumonia, its complication with ICU admission or need of mechanical ventilation or septic shock), as previously reported by Martínez-Baz in a cohort of Health Workers [19]. Still, it should be highlighted that symptomatic patients are over-represented in our study population since not all participating hospitals had a universal antenatal screening program for SARS-CoV-2 infection (so only identified symptomatic cases by passive surveillance) or implemented the program later.

On the other hand, and unlike Tdap and Influenza vaccines (both inactivated vaccines), it has been suggested the potential effect of live attenuated vaccines such as the Bacille Calmette-Guérin (BCG, Mycobacterium bovis vaccine) on reducing SARS-CoV-2 infection, by inducing a trained innate immune response $[20,21]$; this trained immunity is a nonspecific response activated through epigenetic changes in myeloid cells and NK cells that lead to a long-term proinflammatory response and confers cross-protection against other pathogens [22]. Still, the development and administration of SARS-CoV-2 specific vaccines is crucial for limiting the COVID-19 pandemic [23-25], while the previous ones could be 
a complement to SARS-CoV-2 specific vaccines in certain settings until herd immunity is achieved with the latest.

One of the major limitations of our study was the small sample size of patients vaccinated for only Influenza and their characteristics; some of these patients had respiratory comorbidities or other factors in their medical history (not collected here) that recommended the Influenza vaccination. They might have received the vaccine before pregnancy or during the first weeks of pregnancy. The Influenza vaccination campaign (1 October 2019 to 31 January 2020) was prior to COVID-19 lockdown measures in our country, a situation that may have conditioned the subsequent Tdap vaccination (as Tdap vaccine is administered from the 28th week of gestation onwards). Furthermore, the percentage of premature births in this group $(5 / 23,21.7 \%)$ was higher than the observed in the remaining three groups and we should consider that they may have given birth before getting the vaccine.

However, the unusually high proportion of respiratory comorbidities as well as COVID-19 symptoms and their severity in the Influenza vaccine group, is possibly a statistical anomaly due to the small sample size of this group. If there really was an association between the Influenza vaccine and a worse prognosis of the disease, this would have also been seen in the group that received both vaccines (Tdap and Influenza). If this had been the case, we would have had to consider running a multivariable analysis, adjusting for the presence of respiratory comorbidities in these patients.

Another limitation of our study was the lack of information about the exact dates when these vaccines were administered or, in case of multiparous women, if the vaccines were administered in previous pregnancies.

Focusing on the sociodemographic characteristics of the patients, our study supports the previously reported higher risk of poor evolution of the SARS-CoV-2 infection in LatinAmericans [8]. We cannot attribute this prognosis to the vaccination status of these patients and, in the absence of plausible genetic differences, it should be considered that these subjects may be less inclined to follow other preventive measures established for infectious disease control [26]. The objective of this study was not to assess whether there may be a conscious rejection or a difficulty/impossibility of compliance, although we suggest that these findings should be considered in preventive and public health policies [27].

Since differences were not observed in the clinical evolution of SARS-CoV-2 infection in pregnant patients complying with the current vaccination programs, we support the government's recommendation for massive seasonal vaccination against Influenza, and especially for pregnant women, in order to avoid clinical complications in these patients [28,29]. Health education campaigns should be specially targeted to groups less likely to participate in vaccination programs, as well as for a future SARS-CoV-2 vaccination campaign [30].

\section{Conclusions}

No association was observed between the Influenza and/or Tdap vaccination status of patients in the current pregnancy and the clinical presentation of SARS-CoV-2 infection or the severity of symptoms. Adherence to vaccination was observed to be ethnicity dependent; therefore, health education campaigns should be specially targeted to these groups.

Supplementary Materials: The following are available online at https:/ /www.mdpi.com/2076-393 X/9/1/31/s1. Table S1: List of hospitals included in the study $(n=78)$.

Author Contributions: Conceptualization, O.M.-P.; methodology, M.L.d.I.C.C., A.R.V. and O.M.P.; software, M.L.d.l.C.C.; validation, M.L.d.l.C.C., M.B.E.P., M.G.S., L.G.R., M.L.M.-H., A.R.V., P.P.R., A.M.V., C.M.D., S.C.M. and O.M.-P.; formal analysis, M.L.d.l.C.C.; investigation, M.L.d.l.C.C., M.B.E.P., M.G.S., L.G.R., M.L.M.-H., A.R.V., P.P.R., A.M.V., C.M.D., S.C.M., O.M.-P. and Spanish Obstetric Emergency Group; resources, O.M.-P.; data curation, M.L.d.l.C.C.; writing—original draft preparation, M.L.d.I.C.C., M.B.E.P., M.G.S., L.G.R. and O.M.-P.; writing-review and editing, S.C.M.; visualization, M.L.d.I.C.C., M.B.E.P., M.G.S., L.G.R., M.L.M.-H., A.R.V., P.P.R., A.M.V., C.M.D., S.C.M., O.M.-P. and Spanish Obstetric Emergency Group; supervision, O.M.-P.; project administration, O.M.P.; funding acquisition, O.M.-P. All authors have read and agreed to the published version of the manuscript. 
Funding: This research was supported by public funds obtained in competitive calls: Grant COV20/ 00021 from the Instituto de Salud Carlos III-Spanish Ministry of Health, and co-financed with Fondo Europeo de Desarrollo Regional (FEDER) funds.

Institutional Review Board Statement: The study was conducted according to the guidelines of the Declaration of Helsinki, and approved by the Ethics Committee of Puerta de Hierro University Hospital of Majadahonda (protocol code: PI 55/20; date of approval: 23 March 2020).

Informed Consent Statement: Informed consent was obtained from all subjects involved in the study.

Data Availability Statement: Restrictions apply to the availability of these data. Data belongs to the Institute of Health Carlos III and the Spanish Ministry of Health, and are available from the authors with the permission of the Institute of Health Carlos III and the Spanish Ministry of Health.

Acknowledgments: Authors thank José Montes (Office Research) for his support in organizing and cleansing the database. Spanish Obstetric Emergency Group: María Belén Garrido Luque (Hospital Axarquia), Camino Fernández Fernández (Complejo Asistencial de León), Ana Villalba Yarza (Complejo Asistencial Universitario de Salamanca), María Jesús Janeiro Freire (Complejo Hospitalario Universitario A Coruña), María Begoña Dueñas Carazo (Complejo Hospitalario de Santiago de Compostela), Rosario Redondo Aguilar (Complejo Hospitalario Jaén), Ángeles Sánchez-Vegazo García (Complejo Hospitalario San Millán-San Pedro de la Rioja), Esther Álvarez Silvares (Complejo Hospitalario Universitario de Ourense), María Isabel Pardo Pumar (Complejo Hospitalario Universitario de Pontevedra), Macarena Alférez Álvarez-Mallo (HM Hospitales), Paola Carmona Payán (Hospital 12 de Octubre), Víctor Muñoz Carmona (Hospital Alto Guadalquivir, Andújar), Noelia Pérez Pérez (Hospital Clínico San Carlos), Cristina Álvarez Colomo (Hospital Clínico Universitario de Valladolid), Onofre Alomar Mateu (Hospital Comarcal d'Inca), María Luisa Navarro Carrillo (Hospital Costa del Sol), María del Carmen Parada Millán (Hospital da Barbanza), Adrián Martín García (Hospital de Burgos), José Navarrina Martínez (Hospital de Donostia), Carmen Medina Mallén (Hospital Universitario Santa Creu i Sant Pau), Elena Pascual Salvador (Hospital de Minas de Riotinto), Tania Manrique Gómez (Hospital de Montilla y Quirónsalud Córdoba), Marta Ruth Meca Casbas (Hospital de Poniente), Noemí Freixas Grimalt (Hospital Universitari Son Llàtzer), Silvia Mateos López (Hospital de Torrejón), Esther Cánovas Morales (Hospital de Torrevieja), Rosa María Ostos Serna (Hospital de Valme), María Isabel Conca Rodero (Hospital de Vinalopó), Alejandra María Cano García (Hospital del Tajo), Cristina Ruiz Aguilar (Hospital Doctor Peset, Valencia), Susana Fernández García (Hospital General de L’Hospitalet), Mercedes Ramírez Gómez (Hospital General La Mancha Centro), Marina Martí Edo (Hospital General Universitario de Ciudad Real), Rocío López Pérez (Hospital General Universitario Santa Lucía de Cartagena), Carmen Baena Luque (Hospital Infanta Margarita de Cabra), Luz María Jiménez Losa (Hospital Infanta Sofía), Susana Soldevilla Pérez (Hospital Jerez de la Frontera), María Reyes Granell Escobar (Hospital Juan Ramón Jiménez), Manuel Domínguez González (Hospital La Línea), Olga Nieto Velasco (Hospital Quirónsalud Madrid), Magdalena Molina Oller (Hospital Rafael Méndez), Celia Cuenca Marín (Hospital Regional de Málaga), Juan Carlos Wizner de Alva (Hospital San Pedro de Alcántara), Begoña Muñoz Abellana (Hospital Sant Joan de Reus), Encarnación Carmona Sánchez (Hospital Santa Ana. Motril), María Rosa Vila Hernández (Hospital Santa Caterina de Salt), Eva Morán Antolín (Hospital Son Espases), Montse Macià (Hospital Universitari Arnau de Vilanova), Laia Pratcorona (Hospital Universitari Germans Trias i Pujol), Irene Gastaca Abásolo (Hospital Universitario Araba), Begoña Martínez Borde (Hospital Universitario de Bilbao), Óscar Vaquerizo Ruiz (Hospital Universitario de Cabueñes), José Ruiz Aragón (Hospital Universitario de Ceuta), Laura Fuentes Ricoy (Hospital Universitario de Ferrol), María Teulón González (Hospital Universitario de Fuenlabrada), Linda Grace Puerto Tamayo (Hospital Joan XXIII de Tarragona), Pilar Prats Rodríguez (Hospital Universitario Dexeus), Cristina Lesmes Heredia (Hospital Universitario Parc Taulí de Sabadell), J. Román Broullón Molanes (Hospital Universitario Puerta del Mar, Cádiz), María Joaquina Gimeno Gimeno (Hospital Universitario Reina Sofía), Alma Posadas San Juan (Hospital Universitario Río Hortega), Otilia González Vanegas (Hospital Universitario San Cecilio, Instituto de Investigación Biosanitaria, Granada), Ana María Fernández Alonso (Hospital Universitario Torrecárdenas), Lucía Díaz Meca (Hospital Universitario Virgen de la Arrixaca, Murcia), Alberto Puerta Prieto (Hospital Universitario Virgen de las Nieves, Instituto de Investigación Biosanitaria, Granada), María del Pilar Guadix Martín (Hospital Universitario Virgen Macarena), Pablo G. del Barrio Fernández (Hospital Universitario de Getafe), Carmen María Orizales Lago (Hospital Universitario Severo Ochoa, Leganés), José Antonio Sainz Bueno (Hospital Viamed, Grupo Chacón), Mónica Catalina Coello (Hospital Virgen Concha de Zamora), María José Núñez 
Valera (Hospital Virgen de la Luz), Lucas Cerrillos González (Hospital Virgen del Rocío), José Adanez García (Hospital Universitario Central de Asturias), Elena Ferriols-Pérez (Hospital del Mar).

Conflicts of Interest: The authors declare no conflict of interest. The funders had no role in the design of the study; in the collection, analyses, or interpretation of data; in the writing of the manuscript, or in the decision to publish the results.

\section{References}

1. Jehi, L.; Ji, X.; Milinovich, A.; Erzurum, S.; Merlino, A.; Gordon, S.; Young, J.B.; Kattan, M.W. Development and validation of a model for individualized prediction of hospitalization risk in 4536 patients with COVID-19. PLoS ONE 2020, 15, e0237419. [CrossRef] [PubMed]

2. Murillo-Zamora, E.; Trujillo, X.; Huerta, M.; Ríos-Silva, M.; Mendoza-Cano, O. Male gender and kidney illness associated with an increased risk of severe laboratory-confirmed coronavirus disease. BMC Infect. Dis. 2020, 20, 674. [CrossRef] [PubMed]

3. Ortiz-Prado, E.; Simbana-Rivera, K.; Diaz, A.M.; Barreto, A.; Moyano, C.; Arcos, V.; Vasconez-Gonzalez, E.; Paz, C.; SimbanaGuaycha, F.; Molestina-Luzuriaga, M.; et al. Epidemiological, Socio-Demographic and Clinical Features of the Early Phase of the COVID-19 Epidemic in Ecuador. medRxiv 2020. Available online: https:/ / www.medrxiv.org/content/10.1101/2020.05.08.20095 943v2 (accessed on 18 May 2020).

4. Poblador-Plou, B.; Carmona-Pírez, J.; Ioakeim-Skoufa, I.; Poncel-Falcó, A.; Bliek-Bueno, K.; Cano-Del Pozo, M.; Gimeno-Feliú, L.A.; González-Rubio, F.; Aza-Pascual-Salcedo, M.; Bandrés-Liso, A.C.; et al. Baseline Chronic Comorbidity and Mortality in Laboratory-Confirmed COVID-19 Cases: Results from the PRECOVID Study in Spain. Int. J. Environ. Res. Public Health 2020, 17, 5171. [CrossRef] [PubMed]

5. Fink, G.; Orlova-Fink, N.; Schindler, T.; Grisi, S.; Ferrer, A.P.; Daubenberger, C.; Brentani, A. Inactivated Trivalent Influenza Vaccine Is Associated with Lower Mortality among Covid-19 Patients in Brazil. medRxiv 2020. Available online: https://www. medrxiv.org/content/10.1101/2020.06.29.20142505v1 (accessed on 1 July 2020).

6. Reche, P.A. Potential Cross-Reactive Immunity to SARS-CoV-2 From Common Human Pathogens and Vaccines. Front. Immunol. 2020, 11, 586984. [CrossRef]

7. Forster, A.S.; Rockliffe, L.; Chorley, A.J.; Marlow, L.A.V.; Bedford, H.; Smith, S.G.; Waller, J. Ethnicity-specific factors influencing childhood immunisation decisions among Black and Asian Minority Ethnic groups in the UK: A systematic review of qualitative research. J. Epidemiol. Community Health 2017, 71, 544-549. [CrossRef]

8. Ellington, S.; Strid, P.; Tong, V.T.; Woodworth, K.; Galang, R.R.; Zambrano, L.D.; Nahabedian, J.; Anderson, K.; Gilboa, S.M. Characteristics of Women of Reproductive Age with Laboratory-Confirmed SARS-CoV-2 Infection by Pregnancy Status-United States, January 22-June 7, 2020. MMWR Morb. Mortal. Wkly Rep. 2020, 69, 769-775. [CrossRef]

9. Pardilla, M.B.E.; Aguilar, A.C.; Puig, B.M.; Lorenzana, A.S.; de la Torre, I.R.; de la Manzanara, P.H.L.; Bernardo, A.F.; Pérez, Ó.M. Spanish registry of Covid-19 screening in asymptomatic pregnants. Rev. Esp. Salud. Publica. 2020, 94, e202009092.

10. Ministerio de Sanidad, Consumo y Bienestar Social, Gobierno de España. Preguntas y Respuestas Sobre la Vacunación Frente a la Gripe 2020-2021. Available online: https:/ / www.mscbs.gob.es/profesionales/saludPublica/prevPromocion/vacunaciones/ programasDeVacunacion/gripe/faq/Preguntas_respuestas_gripe_ciudadanos_2020-2021.htm (accessed on 14 December 2020).

11. Ministerio de Sanidad, Servicios Sociales e Igualdad, Gobierno de España. Preguntas y Respuestas sobre la Vacunación de la Tosferina en Embarazadas. Available online: https:/ /www.mscbs.gob.es/ciudadanos/proteccionSalud/vacunaciones/docs/ Vacunacion_Tosferina_Embarazadas.pdf (accessed on 14 December 2020).

12. WHO. Clinical Management of COVID-19. Interim Guidance 27 May 2020. WHO/2019-nCoV/clinical/2020.5. Available online: https:/ / www.who.int/publications/i/item/clinical-management-of-covid-19 (accessed on 30 November 2020).

13. Bates, D.; Maechler, M.; Bolker, B.; Walker, S. Fitting Linear Mixed-Effects Models Using lme4. J. Stat. Soft. $2015,67,1-48$. [CrossRef]

14. WHO. Global Vaccine Action Plan 2011-2020; WHO: Geneva, Switzerland, 2013; ISBN 9789241504980.

15. Ministerio de Sanidad, Consumo y Bienestar Social, Gobierno de España. Coberturas de Vacunación, Datos Estadísticos (Actualización Enero 2020). Available online: https:/ / www.mscbs.gob.es/profesionales/saludPublica/prevPromocion/vacunaciones / calendario-y-coberturas/coberturas/home.htm (accessed on 2 December 2020).

16. Lu, P.J.; O’Halloran, A.; Bryan, L.; Kennedy, E.D.; Ding, H.; Graitcer, S.B.; Santibanez, T.A.; Meghani, A.; Singleton, J.A. Trends in racial/ethnic disparities in influenza vaccination coverage among adults during the 2007-08 through 2011-12 seasons. Am. J. Infect. Control. 2014, 42, 763-769. [CrossRef] [PubMed]

17. Hoogink, J.; Verelst, F.; Kessels, R.; Jan van Hoek, A.; Timen, A.; Willem, L.; Beutels, P.; Wallinga, J.; de Wit, G.A. Preferential differences in vaccination decision-making for oneself or one's child in The Netherlands: A discrete choice experiment. BMC Public Health 2020, 20, 828. [CrossRef] [PubMed]

18. Verelst, F.; Kessels, R.; Delva, W.; Beutels, P.; Willem, L. Drivers of vaccine decision-making in South Africa: A discrete choice experiment. Vaccine 2019, 37, 2079-2089. [CrossRef]

19. Martínez-Baz, I.; Trobajo-Sanmartín, C.; Arregui, I.; Navascués, A.; Adelantado, M.; Indurain, J.; Fresán, U.; Ezpeleta, C.; Castilla, J. Influenza Vaccination and Risk of SARS-CoV-2 Infection in a Cohort of Health Workers. Vaccines 2020, 8, 611. [CrossRef] 
20. Berg, M.K.; Yu, Q.; Salvador, C.E.; Melani, I.; Kitayama, S. Mandated Bacillus Calmette-Guérin (BCG) Vaccination Predicts Flattened Curves for the Spread of COVID-19. medRxiv 2020. Available online: https://www.medrxiv.org/content/10.1101/2020 .04.05.20054163v6 (accessed on 30 December 2020). [CrossRef] [PubMed]

21. Miller, A.; Reandelar, M.J.; Fasciglione, K.; Roumenova, V.; Li, Y.; Otazu, G.H. Correlation between Universal BCG Vaccination Policy and Reduced Mortality for COVID-19. medRxiv 2020. Available online: https://www.medrxiv.org/content/10.1101/2020 .03.24.20042937v2 (accessed on 30 December 2020). [CrossRef]

22. Netea, M.G.; Joosten, L.A.B.; Latz, E.; Mills, K.H.G.; Natoli, G.; Stunnenberg, H.G.; ONeill, L.A.J.; Xavier, R.J. Trained Immunity: A Program of Innate Immune Memory in Health and Disease. Science 2016, 352, aaf1098. [CrossRef]

23. Huang, J.; Huang, H.; Wang, D.; Wang, C.; Wang, Y. Immunological strategies against spike protein: Neutralizing antibodies and vaccine development for COVID-19. Clin. Transl. Med. 2020, 10, e184. [CrossRef]

24. COVID-19 Real-Time Learning Network. Vaccines in Development (Last Updated: 24 December 2020). Available online: https: / / www.idsociety.org/covid-19-real-time-learning-network/vaccines/vaccines/ (accessed on 30 December 2020).

25. Polack, F.P.; Thomas, S.J.; Kitchin, N.; on behalf of the C4591001 Clinical Trial Group. Safety and Efficacy of the BNT162b2 mRNA Covid-19 Vaccine. N. Engl. J. Med. 2020, 383, 2603-2615. [CrossRef]

26. How to Protect Yourself and Others. Available online: https://www.cdc.gov/coronavirus/2019-ncov/prevent-getting-sick/ prevention.html (accessed on 30 November 2020).

27. Thomson, A.; Vallée-Tourangeau, G.; Suggs, L.S. Strategies to increase vaccine acceptance and uptake: From behavioral insights to context-specific, culturally-appropriate, evidence-based communications and interventions. Vaccine 2018, 36, 6457-6458. [CrossRef]

28. Grohskopf, L.A.; Sokolow, L.Z.; Broder, K.R.; Olsen, S.J.; Karron, R.A.; Jernigan, D.B.; Bresee, J.S. Prevention and control of seasonal influenza with vaccines: Recommendations of the Advisory Committee on Immunization Practices-United States, 2016-17 influenza season. MMWR Recomm. Rep. 2016, 65, 1-54. [CrossRef] [PubMed]

29. Poehling, K.A.; Edwards, K.M.; Weinberg, G.A.; Szilagyi, P.; Staat, M.A.; Iwane, M.K.; Bridges, C.B.; Grijalva, C.G.; Zhu, Y.; Bernstein, D.I.; et al. The underrecognized burden of influenza in young children. N. Engl. J. Med. 2006, 355, 31-40. [CrossRef] [PubMed]

30. Doherty, M.; Schmidt-Ott, R.; Santos, J.I.; Stanberry, L.R.; Hofstetter, A.M.; Rosenthal, S.L.; Cunningham, A.L. Vaccination of special populations: Protecting the vulnerable. Vaccine 2016, 34, 6681-6690. [CrossRef] [PubMed] 